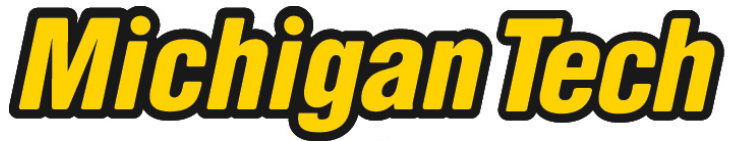 \\ Michigan Technological University Create the Future Digital Commons @ Michigan Tech
}

2013

\section{ANKLE IMPEDANCE AND ANKLE ANGLES DURING STEP TURN AND STRAIGHT WALK: IMPLICATIONS FOR THE DESIGN OF A STEERABLE ANKLE-FOOT PROSTHETIC ROBOT}

Evandro M. Ficanha

Michigan Technological University

Follow this and additional works at: https://digitalcommons.mtu.edu/etds

Part of the Biomechanical Engineering Commons

Copyright 2013 Evandro M. Ficanha

Recommended Citation

Ficanha, Evandro M., "ANKLE IMPEDANCE AND ANKLE ANGLES DURING STEP TURN AND STRAIGHT WALK: IMPLICATIONS FOR THE DESIGN OF A STEERABLE ANKLE-FOOT PROSTHETIC ROBOT", Master'S report, Michigan Technological University, 2013.

https://doi.org/10.37099/mtu.dc.etds/828

Follow this and additional works at: https://digitalcommons.mtu.edu/etds

Part of the Biomechanical Engineering Commons 
ANKLE IMPEDANCE AND ANKLE ANGLES DURING STEP TURN AND STRAIGHT WALK: IMPLICATIONS FOR THE DESIGN OF A STEERABLE ANKLE-FOOT PROSTHETIC ROBOT

By

Evandro M. Ficanha

\begin{abstract}
A REPORT
Submitted in partial fulfillment of the requirements for the degree of MASTER OF SCIENCE

In Mechanical Engineering
\end{abstract}

MICHIGAN TECHNOLOGICAL UNIVERSITY

2013

(C) 2013 Evandro M. Ficanha 
This report has been approved in partial fulfillment of the requirements for the Degree of MASTER OF SCIENCE in Mechanical Engineering.

Department of Mechanical Engineering-Engineering Mechanics

$$
\text { Report Advisor: } \quad \text { Mohammad Rastgaar Aagaah }
$$

$\begin{array}{ll}\text { Committee Member: } & \text { Jason R. Blough } \\ \text { Committee Member: } & \text { Kenton R. Kaufman } \\ \text { Committee Member: } & \text { Nina Mahmoudian } \\ \text { Committee Member: } & \text { Gordon G. Parker }\end{array}$

Department Chair: William Predebon 


\section{TABLE OF CONTENTS}

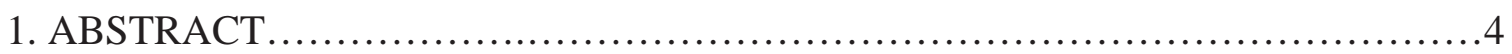

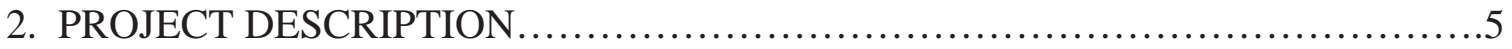

2.1 STOCHASTIC ESTIMATION OF HUMAN ANKLE MECHANICAL IMPEDANCE ..............................................................

2.1.1 Introduction and background...................................

2.1.2 Experiment methodology and results................................5

2.1.3 Results and discussion..........................................

2.1.4 Future work...................................................... 8

2.2 MEASUREMENT OF ANKLE ANGLES DURING STEP TURN AND

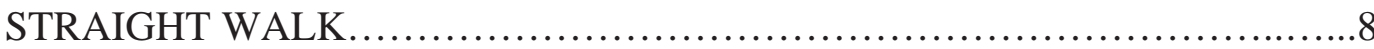

2.2.1 Introduction and background.....................................

2.2.3 Experiment methodology and results............................ 8

2.2.4 Discussion........................................................

2.2.4 Future Work....................................................11

2.3 PROTOTYPE DESIGN OF A CABLE-DRIVEN ANKLE-FOOT

PROSTHESIS WITH TWO CONTROLLABLE DEGREES OF FREEDOM ...11

2.3.1 Introduction......................................................

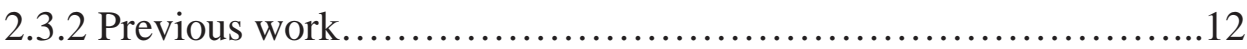

2.3.3 Cable driven design.........................................12

2.3.4 Design analysis: selection and design of the active and passive components........................................................ 14

2.35 Instrumentation and control....................................15

2.3.6 Mechanical Impedance test.......................................16

2.3.7 Maximum force, torque, and range of motion tests.................16

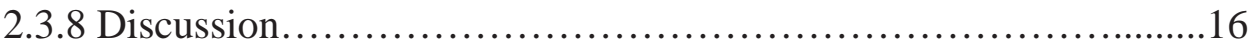

2.3.9 Future Work.................................................

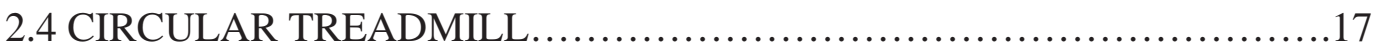

2.4.1Discussion and future work......................................18

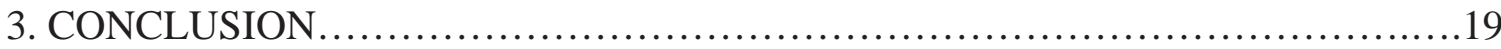

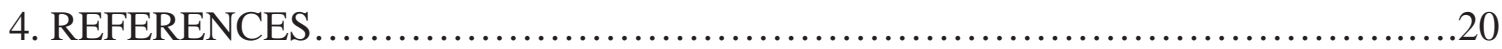

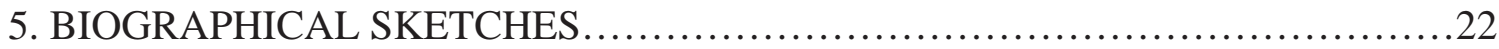




\section{ABSTRACT}

During locomotion, turning is a common and recurring event which is largely neglected in the current state-of-the-art ankle-foot prostheses, forcing amputees to use different steering mechanisms for turning, compared to non-amputees. A better understanding of the complexities surrounding lower limb prostheses will lead to increased health and well-being of amputees. The aim of this research is to develop a steerable ankle-foot prosthesis that mimics the human ankle mechanical properties. Experiments were developed to estimate the mechanical impedance of the ankle and the ankles angles during straight walk and step turn. Next, this information was used in the design of a prototype, powered steerable ankle-foot prosthesis with two controllable degrees of freedom.

One of the possible approaches in design of the prosthetic robots is to use the human joints' parameters, especially their impedance. A series of experiments were conducted to estimate the stochastic mechanical impedance of the human ankle when muscles were fully relaxed and co-contracting antagonistically. A rehabilitation robot for the ankle, Anklebot, was employed to provide torque perturbations to the ankle. The experiments were performed in two different configurations, one with relaxed muscles, and one with $10 \%$ of maximum voluntary contraction (MVC). Surface electromyography (sEMG) was used to monitor muscle activation levels and these sEMG signals were displayed to subjects who attempted to maintain them constant. Time histories of ankle torques and angles in the lateral/medial (LM) directions, inversion-eversion (IE), and dorsiflexionplantarflexion (DP) were recorded. Linear time-invariant transfer functions between the measured torques and angles were estimated providing an estimate of ankle mechanical impedance. High coherence was observed over a frequency range up to $30 \mathrm{~Hz}$. The main effect of muscle activation was to increase the magnitude of ankle mechanical impedance in all degrees of freedom of the ankle.

Another experiment compared the three-dimensional angles of the ankle during step turn and straight walking. These angles were measured to be used for developing the control strategy of the ankle-foot prosthesis. An infrared camera system was used to track the trajectories and angles of the foot and leg. The combined phases of heel strike and loading response, mid stance, and terminal stance and pre-swing were determined and used to measure the average angles at each combined phase. The Range of motion (ROM) in IE increased during turning while ML rotation decreased and DP changed the least. During the turning step, ankle displacement in DP started with similar angles to straight walk and progressively showed less plantarflexion. In IE, the ankle showed increased inversion leaning the body toward the inside of the turn. ML rotation initiated with an increased medial rotation during the step turn relative to the straight walk transitioning to increased lateral rotation at the toe off.

A prototype ankle-foot prosthesis capable of controlling both DP and IE using a cable driven mechanism was developed and assessed as part of a feasibility study. The design is capable of reproducing the angles required for straight walk and step turn; generates $712 \mathrm{~N}$ of lifting force in plantarflexion, and shows passive stiffness comparable to a nonload bearing ankle impedance. To evaluate the performance of the ankle-foot prosthesis, a circular treadmill was developed to mimic human gait during steering. Preliminary results show that the device can appropriately simulate human gait with loading and unloading the ankle joint during the gait in circular paths. 


\section{PROJECT DESCRIPTION.}

\subsection{STOCHASTIC ESTIMATION OF HUMAN ANKLE MECHANICAL IMPEDANCE}

\subsubsection{Introduction and background}

The ankle is of fundamental importance in different tasks such as locomotion and standing, given that it is the first joint to transfer the reactions forces from the ground to the rest of the body. Understanding the mechanical impedance of the human ankle may help to explain its role in the locomotion. During gait, the ankle rotates in all three anatomical planes, suggesting the mechanical impedance modulation occurs in all three degrees of freedom (DOF) of ankle. Ankle mechanical impedance has been studied in sagittal and frontal planes; however, there has been no reported estimation of ankle mechanical impedance in lateral-medial direction in transverse plane.

Previous work estimated the multivariable mechanical impedance of ankle in IE and DP, when the muscles connected to the ankle joint were relaxed and in co-contraction [13]. Ankle impedance during muscle contraction is important since most activities are performed with varying levels of muscle activation. The muscle contraction can be monitored using Surface Electromyography. The sEMG signal amplitudes provide qualitative descriptions of the force and/or speed produced by the muscle and has a near monotonic relationship to muscle force in isometric contraction [4]. Stochastic identification method was used for estimation of multivariable mechanical impedance of ankle. The stochastic method does not require a priori assumption regarding the dynamic characteristics of the system, and so it is a suitable method to estimate the impedance of complex systems [5].

In this section the methodology and the preliminary results for estimation of the mechanical impedance of the ankle in the medial and lateral directions are presented. A wearable ankle robot, Anklebot [5], was used to apply torque perturbations to the ankle and stochastic identification method was employed to estimate the ankle impedance with relaxed and active muscles in DP, ML, and IE.

\subsubsection{Experiment methodology and results}

Five male subjects with no self-reported neuromuscular and biomechanical disorders were recruited for the experiments (ages from 23 to 26 years and body mass index from 18.5 to 27.5). The subjects gave written consents to participate in the experiment, which was approved by the Michigan Tech Institutional Review Board.

In previous work [1, 2], the Anklebot was used for applying the perturbation torques to the ankle in IE and DP directions simultaneously. For this experiment, the same procedures were applied to estimate the impedance in DP and IE, and in addition, a modified setup configuration and robot program was used to generate torque perturbations only in ML directions. The shoe and chair were modified to allow a horizontal placement of the Anklebot actuators (Fig. 1). Pseudo random voltage inputs with similar magnitude and opposite signs were applied to the actuators to generate a rotational motion of the foot about the tibia. The bandwidth of the input signals was 100 $\mathrm{Hz}$ which generated the ML rotation of the ankle with a root-mean-square (rms) of $5.5^{\circ}$, ensuring the induced rotations remain within the natural limits of the joint and preserve the linearity of the system. The robot was attached directly to a custom-made chair and 
mounting bracket underneath the shoe. The weight of the subject's leg and robot was supported by a knee brace and to avoid forward and backwards swinging of the leg due to the actuator forces, a horizontal rod and a shin brace were used to stabilize the leg. Two spherical joints on each end of the rod assured no constraints in the medial-lateral rotation. The torque applied to the ankle and the angles of ankle were measured using the actuators' forces and displacements.

The muscles' activities were monitored using a Delsys ${ }^{\circledR}$ Trigno wireless sEMG system with surface electrodes placed at the bellies of the tibialis anterior (TA) and soleus (SOL) muscles. The sEMG were sampled at $2 \mathrm{kHz}$ and the rms value of a window of $13.5 \mathrm{~ms}$ of data calculated and displayed as a visual feedback to the participant on a computer screen. Before the experiments the subjects were asked to produce their maximum voluntary muscle contraction for a period of 5 seconds so their MVC could be recorded. To avoid exercise fatigue, the participants were instructed to maintain only $10 \%$ MVC of the TA during the muscle co-contraction experiments, where each experiment lasted for 70 seconds. Two separate experiments were performed on the human subjects in ML, one with all the leg muscles relaxed, and the other with 10\% MVC cocontractions. In the DP/IE (Fig. 2) experiment the Anklebot was set to produce perturbations in both DP and IE directions, where the protocol of the experiments was the same as the previous work with the Anklebot [1,2] in both relax and $10 \%$ TA co-contractions.

\subsubsection{Results and discussion}

Figure 2 shows the Bode plot of the ankle impedance in medial-lateral direction for a representative subject in both the active and passive tests. Figure 3 shows the coherences of the estimated frequency response. From the five subjects,

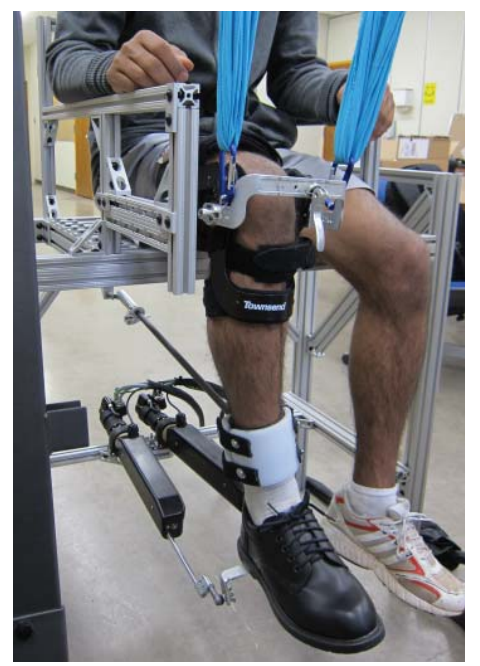

Figure 1. Anklebot mounted to the chair for testing the mechanical impedance in the medial/lateral rotation

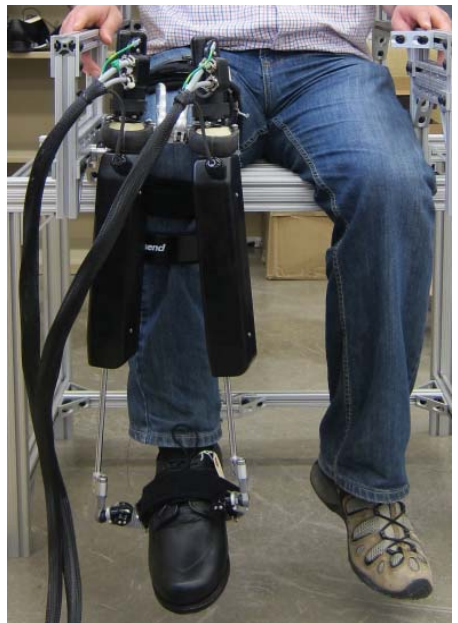

Figure 2. Anklebot mounted to the chair for testing the mechanical impedance in the medial/lateral rotation the mean coherences were 0.87 and 0.88 in the frequency range of up to $50 \mathrm{~Hz}$ for passive and active tests respectively. For up to $30 \mathrm{~Hz}$, the mean coherences were 0.89 and 0.90 showing a reliable linear relation between torques and angles in both active and passive muscle tests within this frequency range.

The average break frequencies were $9.1 \mathrm{~Hz}$ and $6.4 \mathrm{~Hz}$ for passive and active tests, respectively. This break frequency was consistent with the $90^{\circ}$ phase crossing and showed similar behavior as IE and DP impedances [3]. On average, the impedance observed at frequencies below the break frequency for the contraction test was $96 \%$ higher with values of $28.6 \mathrm{~dB}(27 \mathrm{Nm} / \mathrm{rad})$ and $22.8 \mathrm{~dB}(13.8 \mathrm{Nm} / \mathrm{rad})$ for the active and passive tests respectively. The slope of the magnitude plots in both relaxed and active experiments at frequencies above the break frequencies were $54.7 \mathrm{~dB} /$ decade. These results are consistent with previous work in DP and IE where the viscoelastic characteristics of passive tissue and muscle activation direct the ankle behavior at low 
frequencies and foot inertia above the break frequency [3]. The phase plot in Fig. 3 shows a consistent increase in phase for the passive impedance which is consistent with an expected lower response time with lower stiffness.

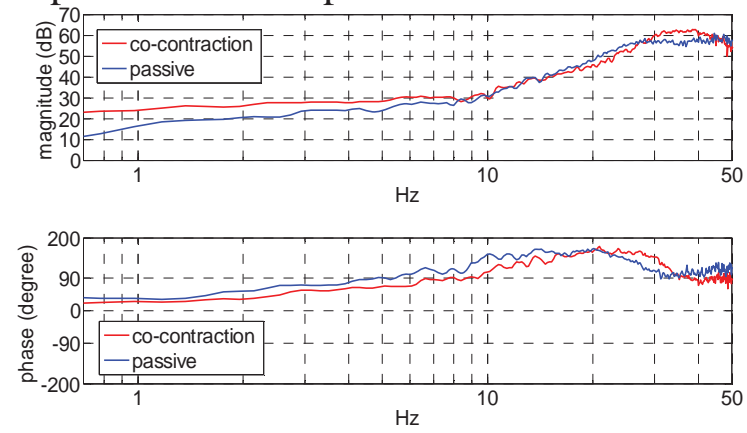

Figure 3. Plots of the magnitude and phase of the impedance in ML of a representative subject
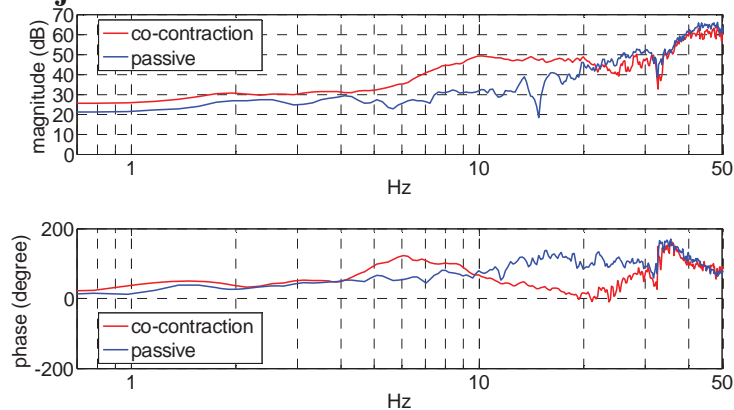

Figure 5. Plots of the magnitude and phase of the impedance in DP of a representative subject
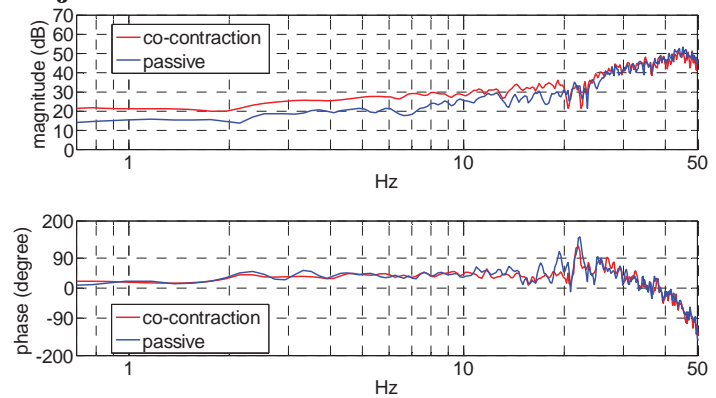

Figure 7. Plots of the magnitude and phase of the impedance in IE of a representative subject

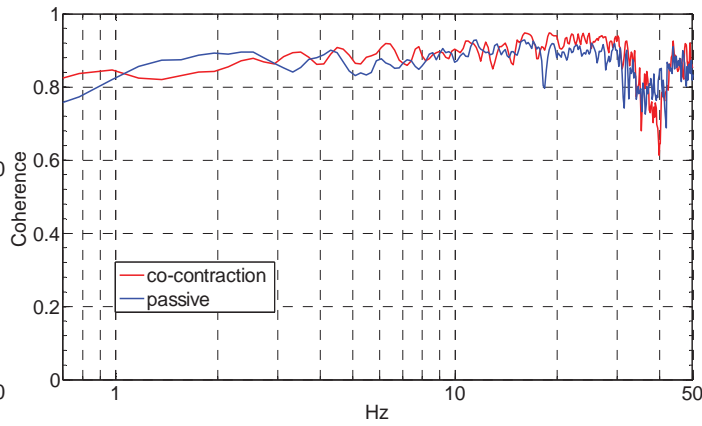

Figure 4. Plot of the coherence of the impedance of a representative subject in ML

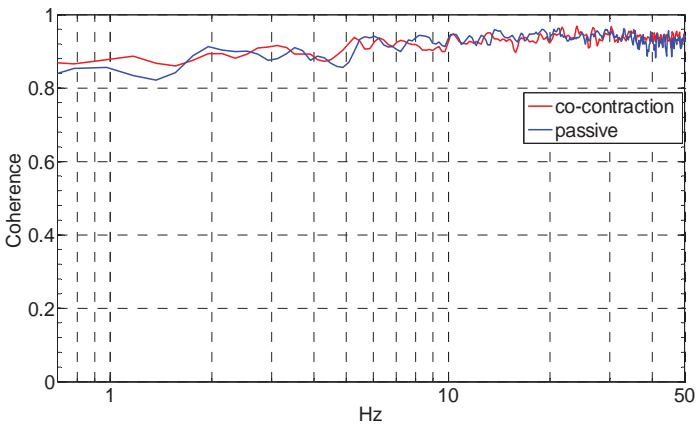

Figure 6. Plot of the coherence of the impedance of a representative subject in DP

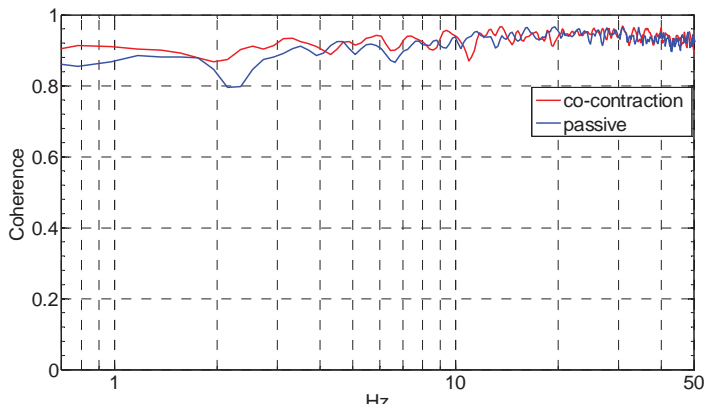

Figure 8. Plot of the coherence of the impedance of a representative subject in IE

DP and IE tests showed similar changes in impedance as ML between relaxed and active tests (Fig. 5 and 7). DP impedance observed at frequencies below the break frequency for the co-contraction test were $86 \%$ higher with values of $31.2 \mathrm{~dB}(47.3 \mathrm{Nm} / \mathrm{rad})$ and 26.9 $\mathrm{dB}(25.4 \mathrm{Nm} / \mathrm{rad})$ for the active and passive tests respectively. IE co-contraction showed an increase of $53 \%$ with values of $23.3 \mathrm{~dB}(18 \mathrm{Nm} / \mathrm{rad})$ and $20.6 \mathrm{~dB}(11.8 \mathrm{Nm} / \mathrm{rad})$ respectively. This indicates that ML has the highest increase in stiffness in co-contraction of the TA and SOL muscles and IE the least. Above break frequency, in both relax and muscle contraction, the slope of the magnitude in the DP was $43.587 \mathrm{~dB} /$ decade and 44.2 $\mathrm{dB} /$ decade in IE. The impedance found in DP and IE both showed an average coherence 
of 0.92 (Fig. 6 and 8) and was not significantly affected by muscle contraction showing a dependable linear relation within this frequency range. The results show similar behavior in the ankles ML, DP, and IE rotations, showing that a similar approach can be used in all three degrees of rotation of the ankle in the implementation of the mechanical impedance in the design of ankle-foot prosthesis.

\subsubsection{Future work}

Since it is of interest to develop lower extremity prosthetic devices with anthropomorphic characteristics, passive or active elements can be incorporated in the design of powered prostheses to generate the desired amount of stiffness in the ankle joint. The impedance of ankle in this report, however, was estimated during non-load bearing conditions. This study may be extended to estimate the time-varying impedance of ankle with similar estimation methods combined with an instrumented walkway as well as indirect methods utilizing a model of ankle impedance in terms of the statistical properties of sEMG signals.

\subsection{MEASUREMENT OF ANKLE ANGLES DURING STEP TURN AND STRAIGHT WALK}

\subsubsection{Introduction and background}

Walking in a straight path requires a complex sequence of muscle activation to modulate the ground reaction forces to keep stability and produce forward motion. Similarly, modulation of the reaction forces to steer the body is required for turning [6]. Two different strategies are commonly used for turning. The spin turn consists of turning the body around the leading leg (e.g. turning right with the right leg in front). The step turn consists of shifting the weight to the leading leg and stepping in the opposite leg while still shifting the body (e.g. turning left with the right leg in front). The step turn is more stable since the base of support is wider [7] and for this reason it was used in this study. It has been shown that the step turn velocity, length, and width are considerably different than the straight walk with higher turning reaction forces [8], and the threedimensional measurement of the ankle angles during step and spin turn have been previously studied [9]. However, it is of interest to measure and compare the ankle angles during heel strike, flat foot, and toe off stages of the gait during straight walk and step turn to better understand the mechanism of turning and use it to develop a prosthetic ankle-foot robot with anthropomorphic characteristics and capable of steering and accommodating ground profile changes.

\subsubsection{Experiment methodology and results}

Five male subjects with no self-reported neuromuscular and biomechanical disorders were recruited for the experiments (ages from 23 to 26 years and body mass index from 18.5 to 27.5). The subjects gave written consent to participate in the experiment that was approved by the Michigan Technological University Institutional Review Board.

Different approaches have been used to measure ankle angles such as using flexible electro-goniometer, electromagnetic tracking devices, and motion capturing cameras [711]. In this study, a motion capture camera system was used to track the rotations of the foot and tibia in this study. The system consisted of 8 cameras in a square formation with 4 cameras at the corners and 4 in between covering a volume of about 16 cubic meters and an area of 12 square meters. The cameras emitted infrared light and captured the 
reflected light from reflectors mounted on the participants with a rate of $250 \mathrm{~Hz}$. Three reflectors are sufficient for the camera system to calculate the position and orientation of a rigid body if each reflector is visible to at least three cameras at that specific point at any time. To avoid the body obstructing the reflectors from being detected by enough cameras, the subjects wore a shoe and a knee brace each mounted with five reflective markers (Fig. 9). The shoe and knee brace assured that the reflectors would not move with respect to each other as they would if they had been mounted on the skin or on the clothes of the participants. All the markers that were mounted on each object (i.e. shoe and knee brace) were defined as single objects and the local coordinate systems were defined at the geometric center of each group of markers (Fig. 10).

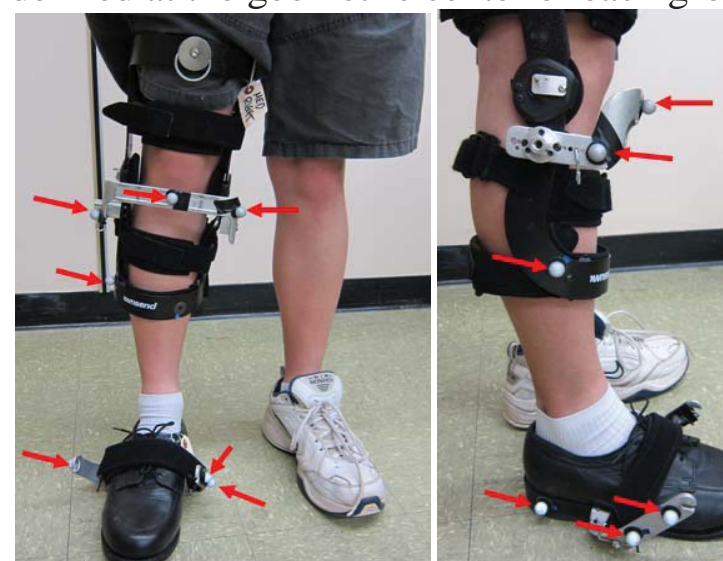

Figure 9. Knee brace and shoe with reflectors.

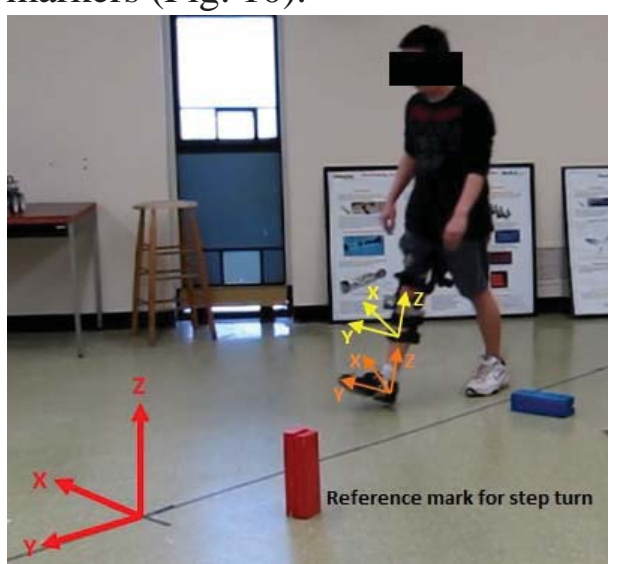

Figure 10. Testing area and reference frames. Red: Global reference frame of the work area. Orange: Local reference frame of the foot. Yellow: Local reference frame of the leg.

The subjects were instructed to walk at a normal pace and an audible metronome was synchronized to their number of steps per minute in an attempt to keep the walking speed constant. The preferred speed for the participants ranged from 88 to 96 steps per minute. The subjects were instructed to walk from outside the field of view of the cameras while following a straight line marked on the floor. When they reached a reference point (Fig. 10 ) on the floor, they performed a $90^{\circ}$ step turn to the left, pivoting on their right leg, and continued walking straight until they were outside the field of view of the cameras. Each subject performed 9 runs. Another step was required to characterize the angles of the foot with respect to the leg using Euler angles. The result includes the position and orientation of the leg and foot relative to the global coordinate system in addition to position and orientation of the foot relative to the coordinate system of the leg. To calculate the orientation of the foot and leg at each state of the gait, the rotation of the foot about the global X axis (Fig. 11) was used to estimate the heel strike (consisting of heel strike and loading response phases), flat foot (mid-stance phase), and toe-off (consisting of terminal stance and pre-swing phases) in each step. Note that the foot angle is positive before heel strike (the heel is on the ground and the toes are elevated), zero when the foot is flat on the ground, and negative at the toe-off (the heel is elevated and the toes are on the ground). The global position of the foot in the $\mathrm{Y}$ axis was used to identify whether the step was a straight or a turning step, as well as to identify the start and the end of the stance periods. 


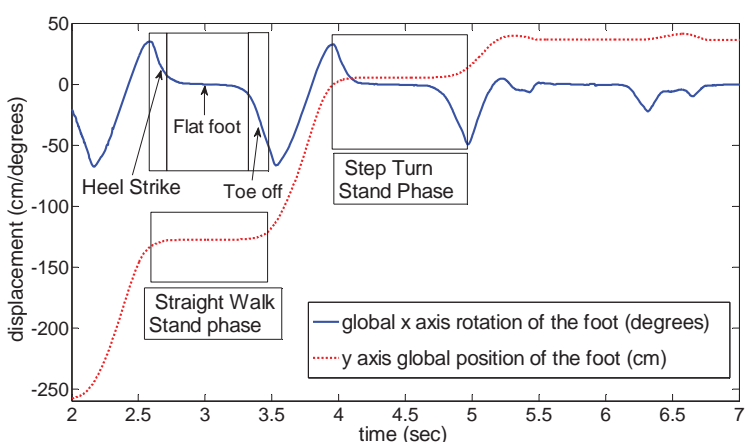

Figure 11. Global $x$ axis rotation and $y$ axis global position of the foot used to identify different states of the gait.

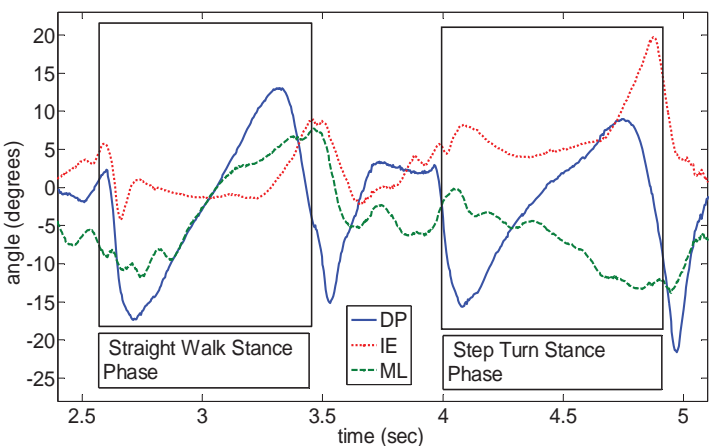

Figure 12. A representative subject's ankle rotations in DP, IE, and ML directions during the straight walk and step turn.

The plots of DP, IE, and ML angles for a representative subject are shown in Fig. 12. The data for each test was divided into 6 segments (heel strike, flat foot, and toe-off from straight and turning steps) and the averages of the DP, IE, and ML angles of each segment were calculated for each of the 45 tests (9 tests on 5 subjects). Table 1 shows the average ROM for the straight step and step turn during the stance periods. The maximum and minimum angles and maximum angular velocities observed for the sample subject in Fig. 12 can also be seen in Table 1. Table 2 shows the average rotations and the difference in angles from the turning step to the straight step in each phase. The range of motion of each subject's ankle about the three axes of the ankle and their average rotations were calculated in each state of the walk. The subjects' range of motion was used to calculate the averaged percent change from straight walk to step turn with respect to their ROM in straight step (Table 2).

Table 1. ROM of ankle during the stance in straight walk and step turn

\begin{tabular}{|c|c|c|c|c|c|c|c|c|}
\hline & \multicolumn{2}{|c|}{$\begin{array}{c}\text { ROM of Straight Step } \\
\text { Stance Period (deg) }\end{array}$} & \multicolumn{2}{c|}{$\begin{array}{c}\text { ROM of Step Turn } \\
\text { Stance Period (deg) }\end{array}$} & $\begin{array}{c}\% \\
\text { Change }\end{array}$ & $\begin{array}{c}\text { Maximum } \\
\text { angle }\end{array}$ & $\begin{array}{c}\text { Minimum } \\
\text { angle }\end{array}$ & $\begin{array}{c}\text { Maximum } \\
\text { angular } \\
\text { velocity. }\end{array}$ \\
\hline Degrees & $\begin{array}{c}\text { Standard } \\
\text { Error }\end{array}$ & Degrees & $\begin{array}{c}\text { Standard } \\
\text { Error }\end{array}$ & & & & \\
\hline IE & 33.9 & 0.65 & 31.6 & 0.62 & -7.4 & $13.03^{\circ}$ & $-21.58^{\circ}$ & $120^{\circ} / \mathrm{s}$ \\
\hline ML & 15.69 & 0.52 & 20.6 & 1.06 & 23.8 & $19.72^{\circ}$ & $-4.248^{\circ}$ & $101^{\circ} / \mathrm{s}$ \\
\hline
\end{tabular}

Table 2. Average angles at different phases of stance in straight step and step turn.

\begin{tabular}{|c|c|c|c|c|c|c|}
\hline & $\begin{array}{c}\text { Straight Step } \\
\text { Average (deg) }\end{array}$ & $\begin{array}{c}\text { Standard } \\
\text { Error }\end{array}$ & $\begin{array}{c}\text { Turning Step } \\
\text { Average (deg) }\end{array}$ & $\begin{array}{c}\text { Standard } \\
\text { Error }\end{array}$ & $\begin{array}{c}\text { Angular } \\
\text { Change (deg)* }\end{array}$ & \% Change* \\
\hline DP heel Strike & -8.72 & 0.80 & -9.68 & 0.95 & -0.95 & -3.0 \\
\hline DP flat foot & 2.34 & 0.63 & 0.36 & 0.64 & -1.98 & -6.5 \\
\hline DP toe off & 10.59 & 1.24 & 1.37 & 0.90 & -9.22 & -29.2 \\
\hline IE heel strike & -1.72 & 0.53 & 5.90 & 0.63 & 7.61 & 46.6 \\
\hline IE flat foot & -2.93 & 0.27 & 6.51 & 0.22 & 9.44 & 60.5 \\
\hline IE toe off & 1.44 & 0.45 & 13.61 & 0.46 & 12.17 & 82.0 \\
\hline ML heel strike & -5.34 & 0.57 & 0.34 & 0.62 & 5.68 & 25.6 \\
\hline ML flat foot & -0.90 & 0.45 & -3.55 & 0.41 & -2.65 & -12.8 \\
\hline ML toe off & 5.53 & 0.32 & -6.53 & 0.65 & -12.06 & -58.0 \\
\hline
\end{tabular}

*Turning step angles - Straight step angles

**From straight to step turn with respect to individual straight walk ROM in stance period. 


\subsubsection{Discussion}

There was a modest decrease in DP ROM during the step turn compared to the straight step (Table 1). IE ROM increased by $23.8 \%$ indicating an increase in IE role during steering. A significantly smaller range of motion in ML may suggest a higher stiffness in that axis of rotation necessary to transfer the reaction forces from the ground to the body. As the step progressed through the gait, differences were observed between the straight step and step turn for all subjects. DP displacement started at a similar initial angle as the straight step $\left(-9.68^{\circ}\right.$ of dorsiflexion) but progressively showed less plantarflexion (1.37 ${ }^{\circ}$ at toe-off compared to $10.37^{\circ}$ in straight walk toe-off) indicating less forward propulsion. IE displacement started with $5.9^{\circ}$ of inversion and increased to $13.6^{\circ}$ at toe-off during the step turn suggesting a gradual increase in inversion to lean the body toward the inside of the turn. At the heel strike of the step turn, ML displacement had an increase of $5.68^{\circ}$ of medial rotation compared to straight walk, suggesting an anticipatory motion of the foot. The difference increased to $12.06^{\circ}$ of lateral rotation at the toe-off generated by the pivoting of the body on top of the foot.

\subsubsection{Future Work}

In future experiments we will increase the number of subjects and also record the angles of the inside leg during straight walk and step turn. The goal is to obtain a library of angles used in regular activities to compare to the performance of prosthetic robots and to be used by the prosthesis controller to estimate the appropriated position of the foot depending on the activity. The developed method will be integrated with the experiment on estimating the ankle impedance during different gait scenarios including turning, steering, walking on level and arbitrary inclined surfaces, to estimate the ankle angles and impedance simultaneously.

\subsection{PROTOTYPE DESIGN OF A CABLE-DRIVEN ANKLE-FOOT PROSTHESIS WITH TWO CONTROLLABLE DEGREES OF FREEDOM}

\subsubsection{Introduction}

It has been shown that the human ankle can be approximated by a spring and damper for walk with slow to normal speed; however, a system with active components is required for walking at faster speeds [12]. Currently, state-of-the-art in lower extremity prostheses are capable of controlling one degree of freedom (DOF) of their ankle joint in the sagittal plane. However, the ankle dynamics in both sagittal and frontal planes are important for increased maneuverability during the gait. Straight walk requires a complex sequence of muscle activation to modulate the ground reaction forces to keep stability and produce forward motion. Similarly, modulation of the reaction forces is required for turning [6].

Much research has focused on straight walk and the dorsi-plantarflexion of the ankle, while less attention has been given to the turning mechanism, even though it plays a major role in locomotion [10]. As an example, amputees use their hip mainly in the sagittal plane to turn in such a way that the outside step length is longer than the inside step length, causing the body to rotate without the need to lean the body inward. However, non-amputees rely more on ankle rotations in the sagittal plane and hip rotations in the coronal plane to lean the body towards the inside of the turn [6]. It is 
estimated that the different strategies are required to compensate for the lack of propulsion in the passive prostheses to increase stability and maneuverability [6]. This evidence suggests that an ankle-foot prosthesis controllable in both dorsiflexionplantarflexion and inversion-eversion directions will provide more assistance in conforming the foot to the ground profile and uneven surfaces, walking in arbitrary directions on the slopes, steering, and turning.

The proposed design will advance state-of-the-art ankle-foot prostheses by providing a steering mechanism that enables control of two degrees of freedom of the ankle to potentially enhance the maneuverability and stability in amputees.

\subsubsection{Previous work}

Different strategies have been used in the design of controllable powered ankle prosthesis in dorsi-plantarflexion. One recent approach uses a spring and motor combination to store energy at heel strike to be released at toe off. This type of design reduces overall energy consumption and motor power requirements, while increases the battery life [13-17]. Pneumatic systems have also been used [18] offering great power to weight ratio for the prosthesis, but this type of design is constrained to lab use due to the weight of air tanks and/or air compressors.

Currently, there are few commercially available transtibial powered prostheses that actively control one DOF in the sagittal plane [19-21]. For example, BiOM provides the necessary energy during toe-off (plantarflexion); therefore, it actively contributes in gait and lowers the metabolic cost. The controller in BiOM allows for gait in different cadences over surfaces with different inclination in uphill and downhill trajectories [19]. Proprio Foot from Ossur uses a stepper motor to provide dorsiflexion motion during swing forward and adjustment of the ankle angle on the surface with different trains. The controller uses a pattern recognition algorithm to adapt to the human's gait continuously [20]. Elan from Endolite uses a hydraulic ankle and the controller provides both dorsiflexion for foot clearance and plantarflexion for support during stance by adjusting the ankle joint resistance [21].

\subsubsection{Cable driven design}

The result from the measurement of the ankle's rotations in three DOF suggested that a steerable mechanism may enhance the gait efficiency by allowing ankle inversioneversion during turning. The design is expected to enable the device to adapt to uneven and inclined grounds and participate in steering, allowing the amputees to benefit more from their prosthesis rather than using their hip joint to stabilize their gait. Hence, a more natural gait may be feasible.

A prototype design of a cable-driven ankle-foot prosthesis with two controllable degrees of freedom was design and built in an effort to study the feasibility of the steering and maneuverability requirements from a 2 DOF ankle (Fig. 13-A and 13-B). The design aims to allows the same ROM and angular velocity in straight walk and step turn as the human ankle while produces enough torque for propulsion.

The device (Fig. 13-A and 13-B) consists of a socket that will be tailored to fit to the residual limb of the amputees (not shown), a pylon (A), two DC motors (E) and planetary gearheads (D) that are powered by two motor controllers (B) and receive signals from a DAQ board (M) connected to a remote computer and two quadrature encoders (I). Two cable drums $(\mathrm{J})$ transfer the required torque to the ankle through the shock-absorbing 
nylon rope $(\mathrm{K})$. The cable is attached to the cable drum and slippage is avoided by looping the cable around 2 bolts, which when tighten, provide enough friction to transfer the forces to the cable (Fig. 13-C). The cable drums are designed to rotate up to 270 degrees to avoid the cable from releasing itself from the drum. A universal joint (F) connects the pylon to the foot and an elastic carbon-fiber plate. Both actuators apply the torque to the foot using a cable-driven mechanism with pulleys (C). The cable is attached to a carbon fiber plate $(\mathrm{H})$ which is connected to a commercial off-the-shelf prosthetic foot (Otto Bock Axtion ${ }^{\circledR}$ ) (L). In the rear side of the carbon fiber plate, the cable is mounted at both sides of the longitudinal axes of the foot. At the front side of the carbon fiber plate, the cable is passed through a pulley (G). The motors are powered by two motor controllers (B). The mechanism is capable of both dorsi-plantarflexion when the motors rotate in opposite directions and inversion-eversion when the motors rotate in the same direction. Also, any combination of DP and IE can be obtainable by combining different amounts of rotation in each motor.

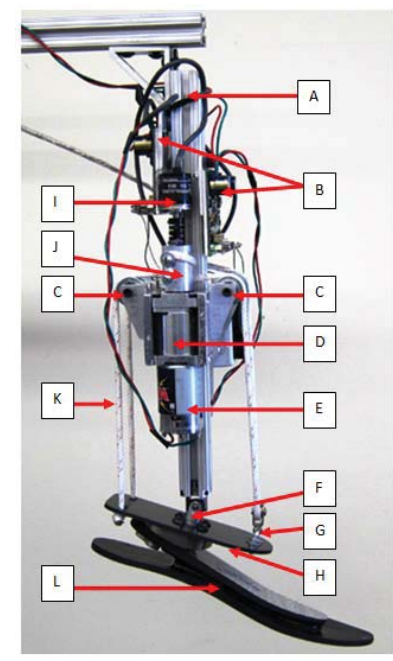

$(13-\mathrm{A})$

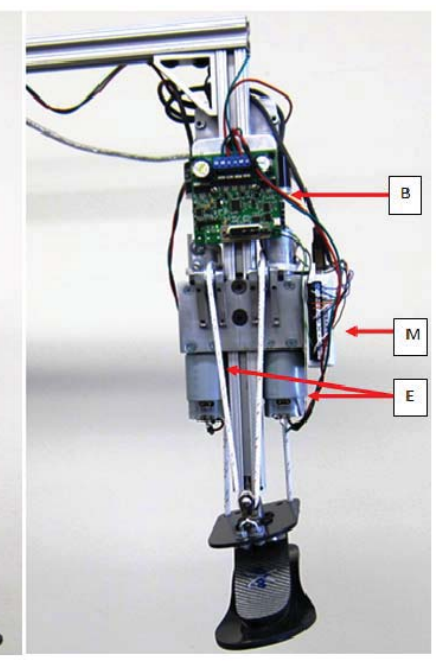

$(13-B)$

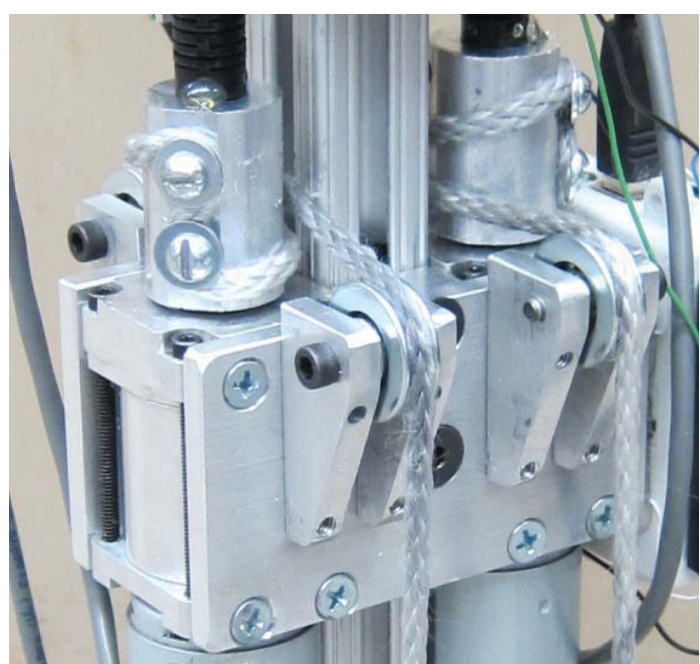

$(13-\mathrm{C})$

Figure 13. Prototype of the steerable powered ankle-foot prosthesis. 13-A: In plantarflexion. 13-B: In inversion. 13-C: Detail of the cable drum and the attachment to the cable to avoid slippage

The proposed mechanical design with 2 DOF uses the fact that three points are sufficient to define a plane in space. If the plane is constrained from translations and has a fixed point of rotation, by defining the position of the 3 points all the rotations of the plane can be achieved. In the proposed design (Fig. 14) 3 points (A, B, C) can be moved in the $\mathrm{Z}$ direction, and thus generate the rotations about the $\mathrm{X}$ and $\mathrm{Y}$ axes which are equivalent to DP and IE, respectively. If the two motors' driving forces are in the same direction, for example in the negative $\mathrm{Y}$ direction, they cause the points $\mathrm{A}$ and $\mathrm{B}$ to move downwards, while point $\mathrm{C}$ moves upwards, resulting in dorsiflexion. If the motors move in opposite directions, for example the right motor apply a force in the positive $\mathrm{Y}$ direction and the left motor apply a force to the negative $\mathrm{Y}$ direction, point A moves upwards, while point B moves downwards, generating an eversion torque in the foot; and since point $\mathrm{C}$ is located on the axis of symmetry of the plate along the $\mathrm{X}$ direction, and the cable goes through a pulley at that point, it neither moves in any direction nor constrains the cable from motion.

Dual motor systems have been previously used to produce the appropriate torques in only DP direction [17]. The proposed design benefits from using both motors 
simultaneously to produce DP torques and uses variations in torque between the 2 motors to produce IE torques. Considering the fact that more power is required in DP than IE during walking, this approach requires 2 identical motors instead of having a larger motor for DP and one smaller motor for IE and does not require any extra hardware other than the universal joint at the ankle when compared to 1 DOF dual motor designs.

The cable driven robot design, besides the ability to control the ankle in 2 DOF, shows advantages over available powered prostheses. The motors and gear boxes are not constrained to the ankle, meaning they can be relocated to accommodate the characteristics and preferences of the user. The system can be moved up or down on the pylon to accommodate to the users' stump and/or to optimize weight distribution. Also, they are not constrained to the leg at all, meaning they could be

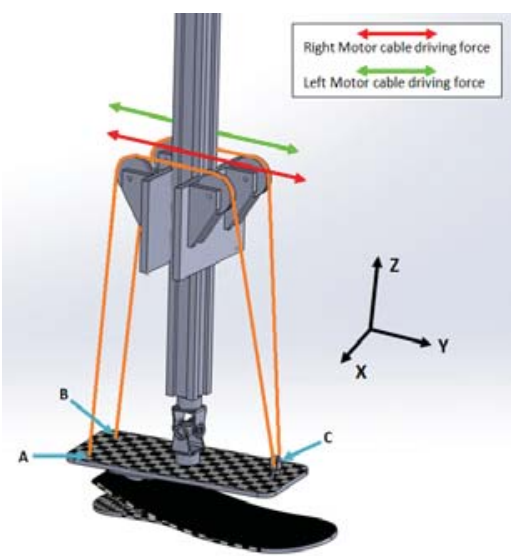

Figure 14. Simplified drawing of the cable driven mechanism showing the points (A, B, and C) of interaction between the cable (orange), carbon fiber plate and motor drive forces. moved elsewhere (to the waist area for example) with the cable connecting to the prosthesis using Bowden cables (similar to the cables running in a bicycle frame) which may be optimal for amputees with long residual stumps. Also the design can be lighter than available powered prostheses since the cable driven mechanisms are capable of torque amplification without the use of gears, and the carbon fiber plate offers shock absorption, energy storage, and passive stiffness at a fraction of the weight of a steel springs.

\subsubsection{Design analysis: selection and design of the active and passive components}

The energy consumption required at each step in an average able-bodied human weighing $70 \mathrm{~kg}$ is $36 \mathrm{~J} / \mathrm{step}$ for walking (250 watts peak power)[13] and torque as high as $140 \mathrm{Nm}$ [15]. These amounts are 35\% higher for an individual with a transtibial prosthesis $[13,22]$; also, the prosthesis is estimated to have $40 \%$ losses resulting on an anticipated peak power consumption of 470 watts and an energy consumption of $68 \mathrm{~J} / \mathrm{step}$. The two brushed DC motors and motor controllers are capable of a continuous torque output of $0.25 \mathrm{Nm}$ at $9200 \mathrm{RPM}$ (producing 240 watts each for a total of 480 watts) and they are connected to gear boxes with a 104:1 reduction gear box. Two 11.1 Volts LiPo batteries connected in series with an energy density of $572 \mathrm{~kJ} / \mathrm{kg}$ are estimated to provide energy for 5800 steps. The current prototype weighs $3 \mathrm{Kg}$ without the battery and socket which is the equivalent weight of the foot-ankle of a $90 \mathrm{~kg}$ person [15].

The motors and gear boxes are cable of a continuous pulling force in the cable (ignoring losses) of $2000 \mathrm{~N}$ at $1.17 \mathrm{~m} / \mathrm{s}$. The moment arm in DP (the distance in the Y axis direction from the center of the universal joint to the cables in the back of the carbon fiber plate) is $57 \mathrm{~mm}$, and the moment arm in IE (the distance in the X axis from the center of the universal joint to the cables in the back of plate) is $28.4 \mathrm{~mm}$. Since both motors contribute to DP, the maximum theoretical continuous torque in DP is $228 \mathrm{Nm}$ at $20.5 \mathrm{rad} / \mathrm{sec}$. Maximum IE torque is $57 \mathrm{Nm}$ at $41 \mathrm{rad} / \mathrm{sec}$. Due to the geometry, there is a $7 \%$ loss in DP torque at $-21.58^{\circ}$ of plantarflexion (maximum DP angle from Table 1 ) and 
a $6 \%$ loss in IE at $19.72^{\circ}$ of inversion (maximum IE angle from Table 1). The torque values and angular velocities are still within the target range even with 50\% losses.

The shock-absorbing nylon rope stretches to provide shock absorption while being soft to the touch [23]. Nylon ropes are strong and flexible which makes it ideal for the design. The carbon fiber plate is $3.175 \mathrm{~mm}$ thick and is a fundamental component of the design. It has been reported that the average plantarflexion stiffness at 50\% MVC is 143 $\mathrm{Nm} /$ deg and is near constant from 30\% to $80 \%$ MVC [24], thus the carbon fiber plate was designed to have this stiffness in DP and $25 \%$ of this value (36 Nm/deg) in IE. The carbon fiber plate acts as a spring connected in series between the cable and foot. The cable need to be always in tension to assure the proper control over the foot, causing the carbon fiber plate to be always under a bending moment.

\subsubsection{Instrumentation and control}

Presently, two optical quadrature encoders (200 pulses per revolution) provide position feedback to a remote computer that uses a proportional plus rate controller to control the prosthesis position. The overall control architecture of the prosthesis can be seen in Fig. 15, and the block diagram of the controller can be seen in Fig. 16.

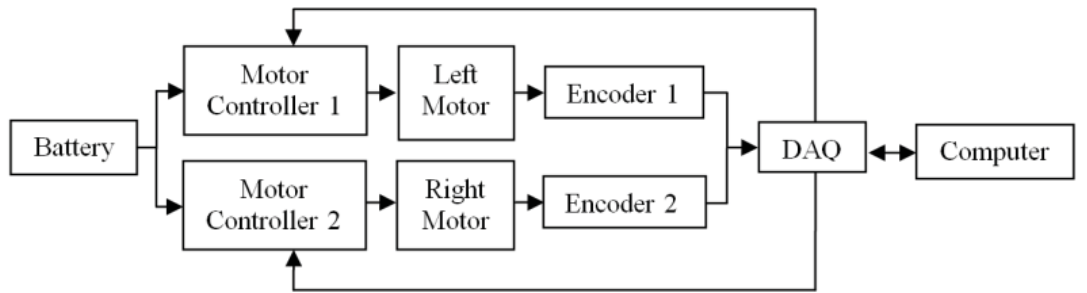

Figure 15. Overall control architecture of the robot

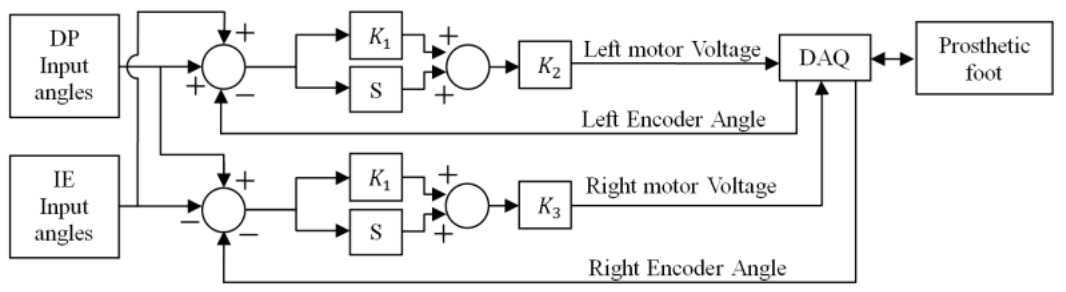

Figure 16. Block diagram of the robot controller

The controller uses a look up table with the recorded angles captured with the motion camera system in both DP and IE. The input and output angles to the controller can be seen in Fig. 17 where the robot is moving at 50\% of walking speed. For ease of comparison, the output plots have a time shift to remove the 80 milliseconds delay of the output. Also, all signals are filtered with a low-pass filter with a cutoff frequency of $5 \mathrm{~Hz}$ to remove frequency components from the input that are beyond the bandwidth of the motors and sensor noise from the output signal.
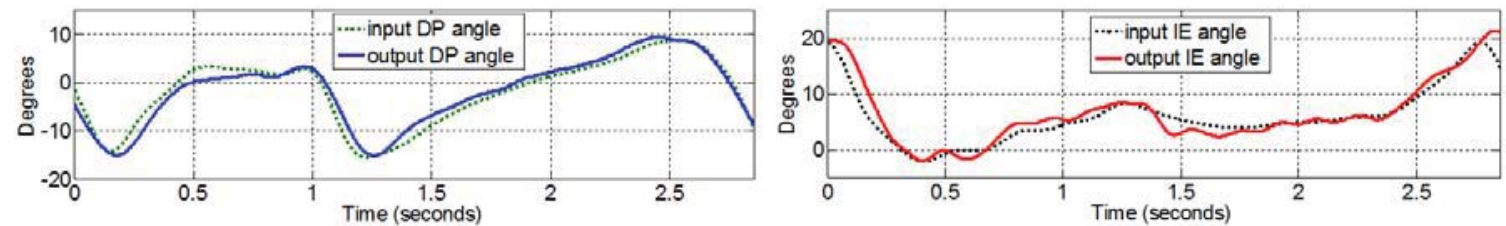

Figure 17. Input and compensated output for time delay ( 80 milliseconds) of the ankle-foot prosthesis during swing and stance periods of a step turn at $50 \%$ of walking speed with no load. 


\subsubsection{Mechanical Impedance test}

The purpose of this test was to identify the passive impedance of the prosthetic device and compare it to the impedance of human subjects. The impedance test setup was similar to the procedure used in the human tests and all the controllers of the prosthesis were turned off.

The setup of the experiment consists of attaching both robots mechanically to each other (Fig. 20). The OttoBock Axtion ${ }^{\circledR}$ foot and its rubber foot shell were inserted in the same type of the shoe used in human tests to assure the experiments were consistent. The results from the mechanical impedance tests in the human and the prosthesis can be observed in Fig. 18 and 19.

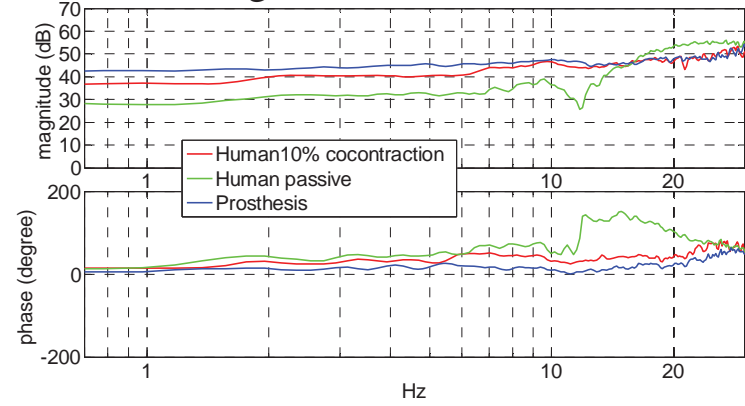

Figure 18. Plots of the Magnitude and phase of the impedance in DP rotation of the prosthetic robot and a human subject with relaxed muscles and $\mathbf{1 0 \%}$ co-contraction.

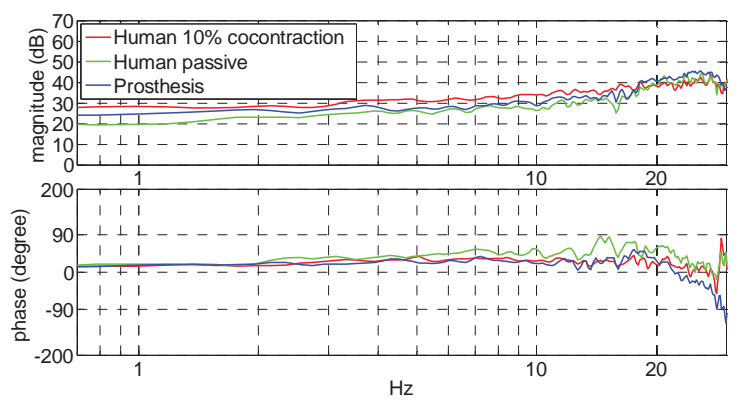

Figure 19. Plots of the magnitude and phase of the impedance in IE rotation of the prosthetic robot and a human subject with relaxed muscles and $10 \%$ co-contraction.

\subsubsection{Maximum force, torque, and range of motion tests}

A Kistler ${ }^{\circledR}$ Type 5233A force plate was used to measure the maximum amount of force produced by the ankle-foot prosthesis with a step input plantarflexion signal. The robot's shank was constrained in the $\mathrm{z}$ direction with the intention to measure the stall torque of the ankle. The robot was capable of generating a lift force of $712 \mathrm{~N}$, which corresponds to 103.2Nm of torque. The maxim IE torque can be calculated directly from the DP and the robot's mechanical characteristics as previous described to an estimated 25.8 $\mathrm{Nm}$. In the current configuration, the maximum range of rotation recorded from the position encoders in DP is $49^{\circ}$ and in IE was $98^{\circ}$ due to the range of rotation of the cable drum. Both DP and IE ranges are within the set goals.

\subsubsection{Discussion}

The implemented mechanical design, although in early stages of development, showed anthropomorphic characteristics. The design was successful at mimicking human motion, and showed comparable mechanical

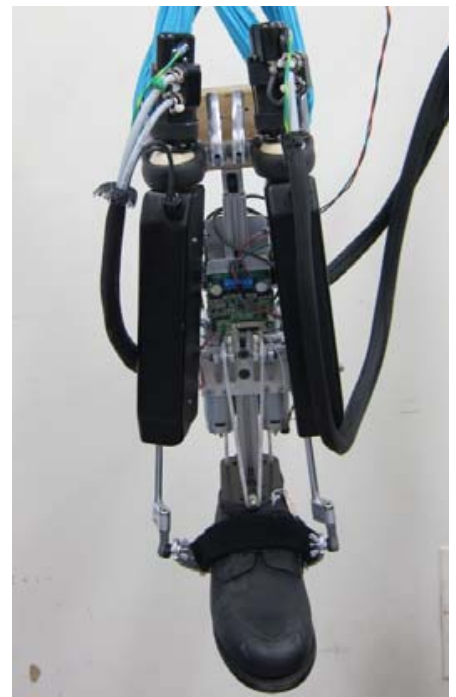

Figure 20. Measurement of the prosthetic foot mechanical impedance using the Anklebot characteristics. The results of the mechanical impedance experiment (Fig. 18) resulted on a passive stiffness of the prosthesis that was $42.62 \mathrm{~dB}(135 \mathrm{Nm} / \mathrm{rad})$ in $\mathrm{DP}$ at $1 \mathrm{~Hz}$, which is close to the design objective of $143 \mathrm{Nm} / \mathrm{rad}$. Also, it shows a relatively linear impedance and phase over the frequency range of 0 to $5 \mathrm{HZ}$. The human subject shows 
less overall stiffness in DP in both passive and co-contraction testes. The prosthesis's IE impedance was within the active and passive stiffness of the human ankle with $24.24 \mathrm{~dB}$ (16 Nm/rad) at $1 \mathrm{HZ}$, which is $46 \%$ lower than the design objective.

As expected, during the tests, the carbon fiber plate was flexing due to the applied torque, and since the encoders read the cable displacement instead of foot angles, the controller perceives the deflection of the carbon fiber plate as an angular change in the foot. This caused the position controller to reduce the applying torque prematurely, and thus the values were less than what was anticipated, although it was still powerful enough to lift a $72 \mathrm{~kg}$ person.

Testing the range of motion in IE, it was found that the IE motion becomes unstable at angles above 62 degrees (if forced by an external force). This is the equivalent of rolling the ankle, which is a common injury among active people and are mostly in inversion [25]. In the robot, ankle roll happens when either points A or B (Fig. 14) crosses the $\mathrm{Y}$ axis. At this point, the tension in the cable, which is applying a torque against the disturbance force, changes the direction of the torque and makes the ankle unstable. The maximum rotation in IE (Table 1 ) is $19.72^{\circ}$, and thus instability should not be a problem during normal walk.

\subsubsection{Future work}

Future robot designs may incorporate a hard stop to avoid excessive rotation of the ankle in presence of a strong IE disturbance torque. The designs will incorporate a selection of passive elements based on the characteristics of the ankle inertia, damping, and stiffness derived from the estimated impedance of the ankle $[1,2,26]$. This includes the addition of an elastomer to provide anthropomorphic characteristics and passive stiffness in both DP and IE. The control of the ankle joint will be based on mimicking the time-varying impedance of the ankle during different phases of stance period while providing the required torque. This approach is similar to the control approach suggested and implemented in [27]. In our prototype, however, the control algorithm will regulate the impedance in two DOF and the number of modes in the finite states control architecture will be determined based on the estimation of the time-varying ankle impedance at different phases of the stance period. A perturbation walkway is under development for collecting necessary data and the impulse response identification method will be used for estimation of the time-varying impedance of the ankle during gait [28]. Strain gages will be placed on the foot allowing the calculation of the applied torque and ground reaction forces providing information about the state of the gait such as heel strike, flat foot, toe off, and swing phases and the forces being applied to the foot. The state of the gait, look-up tables of prerecorded ankle angles data, and the force feedback, will be utilized by the impedance controller to calculate the necessary position and torque. A FPGA board will replace the remote computer of the current prototype and faster brushless motors with higher power-to-weight ratio and efficiency will be used to decrease the weight of the robot and its time delay while increasing battery life.

\subsection{CIRCULAR TREADMILL}

It is of interest to evaluate the prosthetic robot and compare it to the human ankle. One of the challenges of testing prosthetic devices is that they usually include a human using the device, making the tests non repeatable and inconsistent. To test the ankle-foot robot, a powered circular treadmill was developed, allowing the ankle robot to be tested 
during walk in a turning pattern without the need of human interaction. The treadmill can also be used by unimpaired humans for comparison with the robot.

A picture of the circular treadmill can be seen in Fig. 21. The circular treadmill is composed of a wooden disk with a $1 \mathrm{~m}$ radius $(\mathrm{A})$. 8 coaster wheels (B) are connected to the outside lower edge of the disk for weight bearing, and a heavy-duty turn table (not

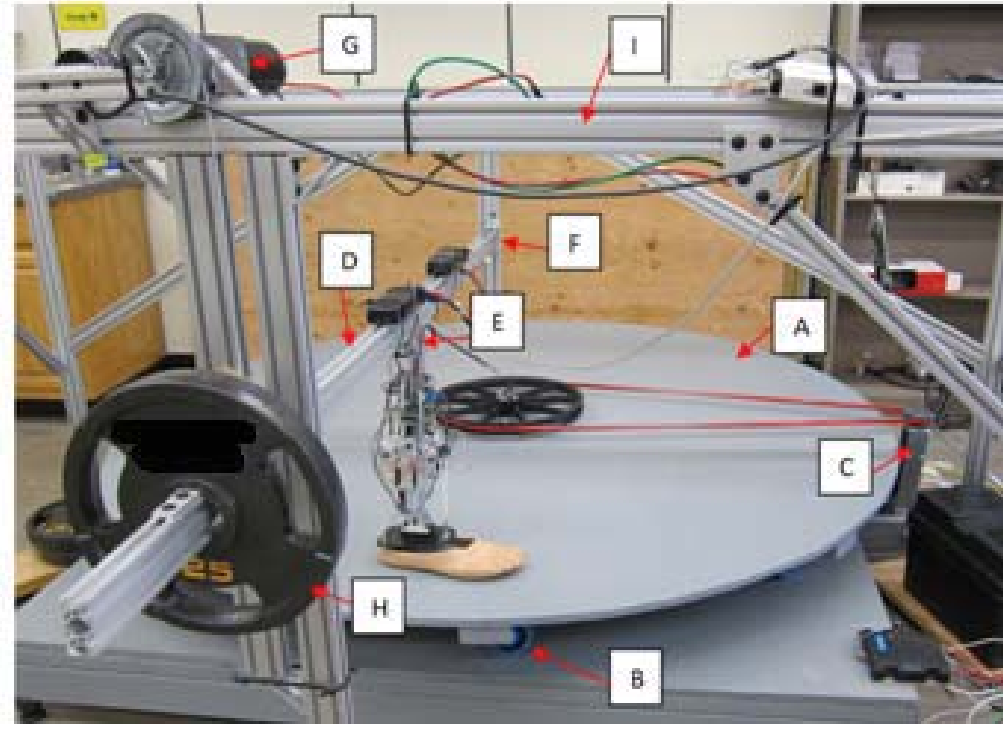

Figure 21. Circular treadmill and its main components visible) is connected in the center for both weight- bearing and constraining the disk from sliding in the horizontal plane. A motor and planetary gear box (C) powers the rotation of the disk. The prosthetic foot is connected to a horizontal beam (D) by a universal joint (E) which acts as a passive knee. The beam has one end connected to a pivot (F) and the other end connected to a cable connected to a motor and gear box (G) which can raise and lower the beam and robot. The same end of the beam is connected to a weight $(\mathrm{H})$ which is supported by the prosthetic leg when the weight is lowered or by the motor and gear box when the beam is raised. The prosthetic foot, beam, motor and gear box, and weight are attached to an aluminum frame (I) which is not coupled to the treadmill in any way other than through the prosthetic foot.

The platform can lift and lower the foot and apply weight emulating a human walk. The radius of turn of each step can be increased or decreased by sliding the frame (I) so the foot is closer or farther away from the center of the treadmill. Also the weight supported by the leg can be controlled by adding or removing weights or by sliding the joint (E) closer or farther away from the weight $(\mathrm{H})$.

The speed of the treadmill disk is controlled using an open loop controller. The final gear ratio is 341/1 resulting in a maximum walking speed of $1.63 \mathrm{~m} / \mathrm{sec}$ which is sufficient considering the average preferred human walking speeds for young adults is $1.30 \mathrm{~m} / \mathrm{s}$ [29]. The lifting mechanism uses a PD controller with feedback from a quadrature encoder and the input is a sine wave with the same period as the walking gait. The amplitude and time shift are depended on prosthetic ankle-foot tuning, amount of weight being used, and position of the prosthesis with respect to the frame and treadmill. The lifting mechanism is capable of lifting $118 \mathrm{~kg}$ at $10.6 \mathrm{~m} / \mathrm{s}$, although the weight supported by the foot is higher and depends on the position of the shank of the robot with respect to the beam (D). Figure 22 shows the foot at different states of the gait while walking on the treadmill.

\subsubsection{Discussion and future work}

The treadmill provides a platform for testing the ankle-foot prosthesis, which allows for consistent and repeatable measurements. In the future, a motion capture camera system 
will be installed allowing the measurement of the angles of the prosthesis during the gait. Also, the camera system will be used to measure the human gait while walking on the treadmill for comparison. The treadmill will also have modular terrain profile elements which can be added to simulate off camber walk, and ascending/descending/traversing the slopes, etc. These terrain profile elements will be used to tune the ankle-foot controller for disturbance rejection and surface profile adaptation.

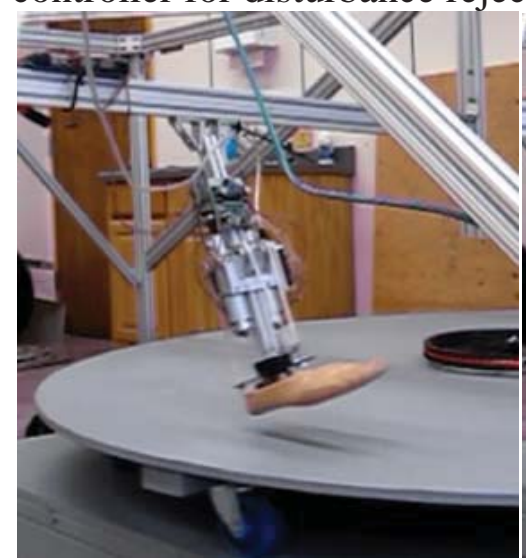

(A)

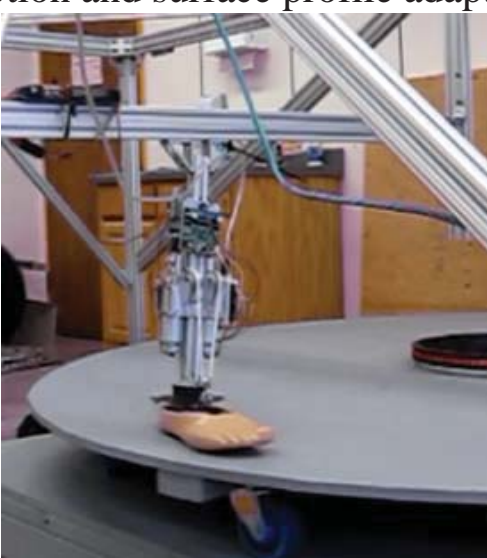

(B)

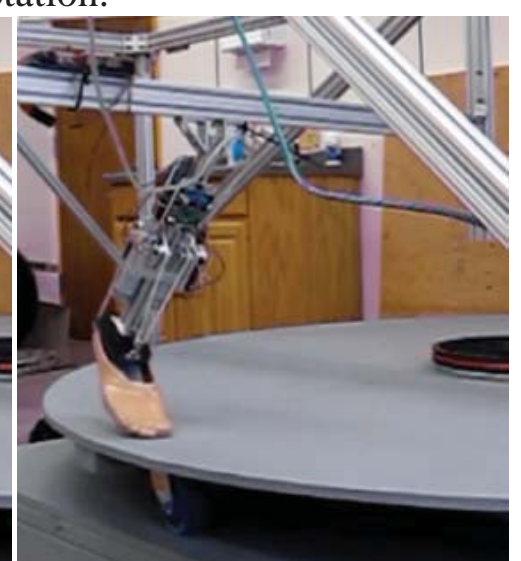

(C)

Figure 22. Circular treadmill and prosthetic ankle-foot robot. A- Swing phase. B- Flat foot (all the weight is on the foot). C- Toe off.

\section{CONCLUSION}

The ankle mechanical impedance measurement provides information about the stiffness of the ankle that will be useful in the design of a controller for the ankle-foot prosthesis with force plus position feedback. The data that has been collected so far provides information about the ankle with no load, thus more experiments will be required to estimate the mechanical impedance at different states of the gait including load-bearing phases.

Strain gages and force sensitive resistor (FSR) in the foot will provide information about heel strike, flat foot, toe off, and swing phases. Also, these sensors will allow the prosthesis to identify slope changes and disturbances. The controller will have a library with the approximate trajectory of the foot for different gait strategies. More data needs to be collected to include position data for different gaits such as walking uphill, downhill, climbing steps, braking, etc.

The current ankle-foot robot shows promising results. Future generation with faster motors and strain gages should allow for better performance and the development of an impedance controller to properly mimic human gait. Also it will be explored how the motors, gear boxes, electronics, and batteries would be placed in a flexible configuration, for example by using Bowden cables, to transfer the power to the ankle joint. This approach will make the ankle-foot very lightweight, compact, and customizable. The circular treadmill will allow the robot to be tested with surface irregularities, different radiuses of turning, and different weights to be compared to human gait in similar conditions. 


\section{REFERENCES}

[1] M. Rastgaar, et al., "Stochastic estimation of multi-variable human ankle mechanical impedance," in ASME Dynamic Systems and Control Conference, Hollywood, CA, 2009.

[2] M. Rastgaar, et al., "Stochastic estimation of the multi-variable mechanical impedance of the human ankle with active muscles," in ASME Dynamic Systems and Control Conference, Boston, MA, 2010.

[3] H. Lee, et al., "Quantitative Characterization of Steady-State Ankle Impedance with Muscle Activation," in ASME Dynamic Systems and Control Conference Cambridge, MA, 2010.

[4] C. J. D. Luca, "The Use of Surface Electromyography in Biomechanics," Journal of Applied Biomechanics, vol. 13, pp. 135-163, 1997.

[5] A. Roy, et al., "Robot-aided neurorehabilitation: A novel robot for ankle rehabilitation," IEEE Transactions on Robotics and Automation, vol. 25, pp. 569582, 2009.

[6] J. D. Ventura, et al., "Compensatory mechanisms of transtibial amputees during circular turning," Gait \& Posture, vol. 34, pp. 307-312, 2011.

[7] K. Hase and R. B. Stein, "Turning Strategies During Human Walking," J Neurophysiol., vol. 81, pp. 2914-2922, 1999.

[8] B. C. Glaister, et al., "Ground reaction forces and impulses during a transient turning maneuver," J. Biomechanics, vol. 41, pp. 3090-3, 2008.

[9] P. D. M.J.D. Taylor, S.C. Strike, "A three-dimensional biomechanical comparison between turning strategies during the stance phase of walking," Human Movement Science, vol. 24, pp. 558-573, 2005.

[10] M. S. Orendurff, et al., "The kinematics and kinetics of turning: limb asymmetries associated with walking a circular path," Gait \& Posture, vol. 23, pp. 106-111, 2006.

[11] (Computing Community Consortium, May 21, 2009, A Roadmap for US Robotics, From Internet to Robotics. Available: http://www.usrobotics.us/reports/CCC\%20Report.pdf

[12] D. S. C. Andrew H. Hansen, Steve C. Miff, Steven A. Gard, Kent P. Mesplay, "The human ankle during walking: implications for design of biomimetic ankle prostheses," Journal of Biomechanics, vol. 37, pp. 1467-1474, 2004.

[13] J. K. Hitt, et al., "An Active Foot-Ankle Prosthesis With Biomechanical Energy Regeneration," J. Med. Devices, vol. 4, 2010. 
[14] P. A. V. Bryan J. Bergelin, "Design of an Active Ankle-Foot Prosthesis Utilizing a Four-Bar Mechanism," Journal of Mechanical Design, vol. 134, 2012.

[15] J. W. Samuel K. Au, and Hugh Herr "Biomechanical Design of a Powered AnkleFoot Prosthesis," presented at the International Conference on Rehabilitation Robotics,, Noordwijk, The Netherlands, 2007.

[16] S. K.-W. Au, "Powered Ankle-Foot Prosthesis for the Improvement of Amputee Walking Economy," Mechanical Engineering, Mechanical Engineering, MASSACHUSETTS INSTITUTE OF TECHNOLOGY, 2007.

[17] J. Hitt, et al., "BIONIC RUNNING FOR UNILATERAL TRANSTIBIAL MILITARY AMPUTEES," in 27th Army Science Conference (ASC), Orlando, Florida, 2010.

[18] D. P. Ferris, et al., "An Ankle-Foot Orthosis Powered by Artificial Pneumatic Muscles," Journal of Applied Biomechanics, vol. 21, pp. 189-197, 2005.

[19] 2012, Bionic Technology with Powered Plantar Flexion. Available: http://www.iwalkpro.com/Prosthetists.html

[20] 2012, The technology behind the PROPRIO FOOT® from Össur. Available: http://www.ossur.com/?PageID=15736

[21] 2012, endolite, élan. Available: http://www.endolite.com/products/elan

[22] S. S. Rao, et al., "Segment velocities in normal and transtibial amputees: prosthetic design implications.," IEEE Trans Rehabil Eng. , vol. 6, pp. 219-26, 1998.

[23] 2013. Shock-Absorbing Nylon Rope. Available: http://www.mcmaster.com/\#standard-fibrous-cords/=n28a38

[24] T. Sinkjaer, et al., "Muscle stiffness in human ankle dorsiflexors: Intrinsic and reflex components," Journal of Neurophysiology, vol. 60, pp. 1110-1121, 1998.

[25] A. Saripalli and S. Wilson, "Dynamic Ankle Stability and Ankle Orientation."

[26] H. Lee, et al., "Multivariable static ankle mechanical impedance with relaxed muscles," Journal of Biomechanics, vol. 44, pp. 1901-1908, 2011.

[27] F. C. Sup, "A Powered Self-Contained Knee and Ankle Prosthesis For Near Normal Gait in Transfemoral Amputees," Ph.D., Mechanical Engineering, Vanderbilt University, Nashville, Tennessee, 2009.

[28] H. Lee, et al., "Linear Time-Varying Identification of Ankle Mechanical Impedance During Human Walking," in ASME 2012 5th Annual Dynamic Systems and Control Conference, Fort Lauderdale, FL, USA, 2012.

[29] H. G. Kang and J. B. Dingwell, "Separating the effects of age and walking speed on gait variability," Gait Posture, vol. 27, pp. 572-527, 2008. 


\section{BIOGRAPHICAL SKETCHES}

1- E. M. Ficanha, et al., "Ankle Angles during Step Turn and Straight Walk: Implications for the Design of a Steerable Ankle-foot Prosthetic Robot " in ASME Dynamic Systems and Control Conference, Palo Alto, CA, 2013.

2- M. R. Aagaah and E. M. Ficanha, "Powered ankle-foot prosthesis with two controllable degrees of freedom” USA Patent, 2012.

3- M. Rastgaar, et al., "Multi-Directional Dynamic Mechanical Impedance of the Human Ankle; a Key to Anthropomorphism in Lower Extremity Assistive Robots," in Neuro-robotics: From brain machine interfaces to rehabilitation robotics, P. Artemiadis, Ed. ed: Springer, 2014 (in press).

4- E. M. Ficanha and M. Rastgaar, "Multi-axis Capability for Powered Ankle-foot Prostheses" in Neuro-robotics: From brain machine interfaces to rehabilitation robotics, P. Artemiadis, Ed., ed: Springer, 2014 (in press). 